Document downloaded from:

http://hdl.handle.net/10251/150426

This paper must be cited as:

Bernat Pérez, N.; Cháfer Nácher, MT.; González Martínez, MC.; Rodríguez García, J.; Chiralt, A. (2015). Optimisation of oat milk formulation to obtain fermented derivatives by using probiotic Lactobacillus reuteri microorganisms. Food Science and Technology International. 21(2):145-157. https://doi.org/10.1177/1082013213518936

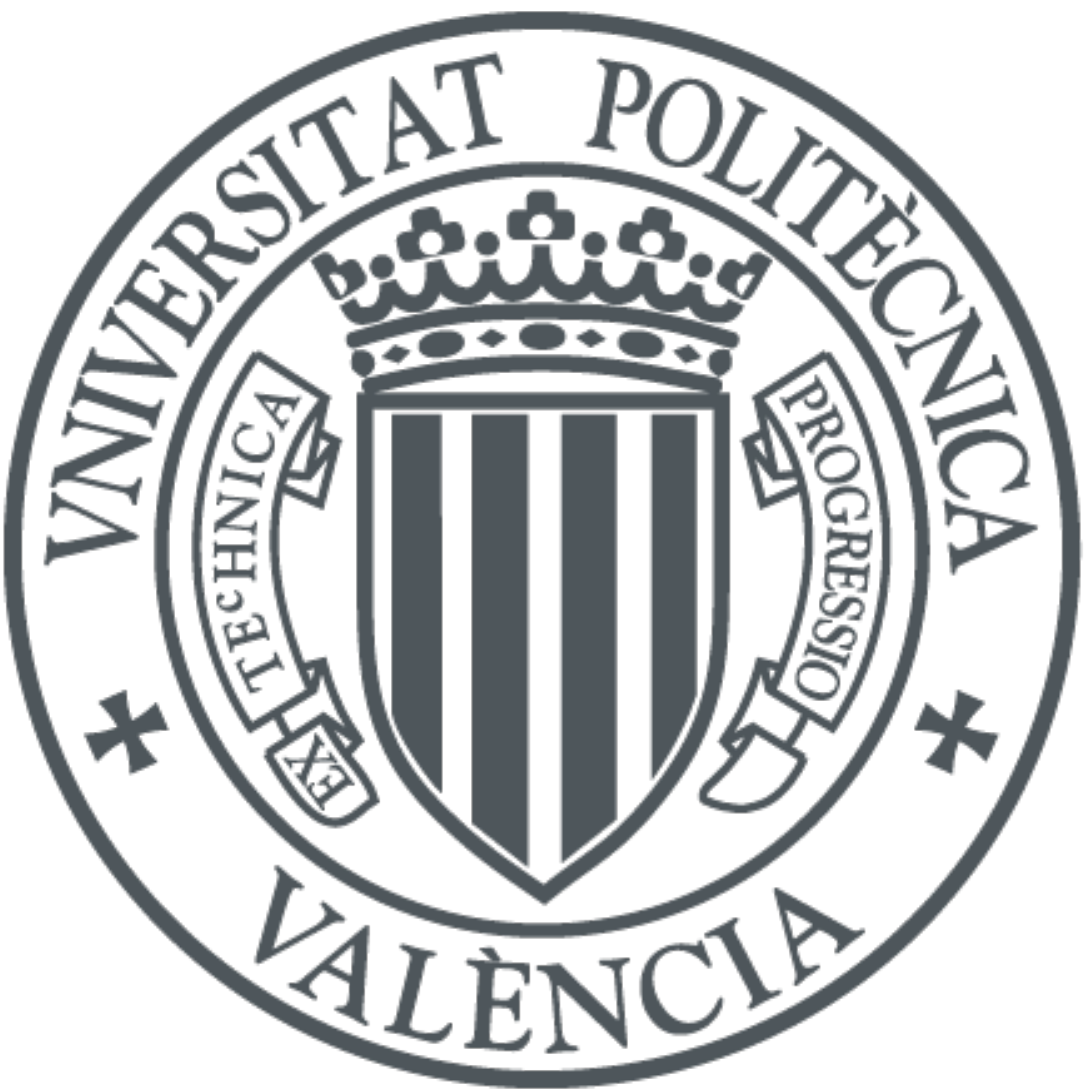

The final publication is available at

https://doi.org/10.1177/1082013213518936

Copyright SAGE Publications

Additional Information 


\title{
Optimisation of oat milk formulation to obtain fermented derivatives by using probiotic Lactobacillus reuteri microorganisms
}

\author{
Bernat N. ${ }^{\text {, }}$ Cháfer M. ${ }^{\mathrm{a}}$, González-Martínez Ca, Rodríguez-García J. ${ }^{\mathrm{b}}$, Chiralt A. ${ }^{\mathrm{a}}$ \\ ${ }^{a}$ Institute of Food Engineering for the Development \\ ${ }^{\mathrm{b}}$ Research Group of Food Microstructure and Chemistry \\ Universitat Politècnica de València. Camino de Vera s/n. 46022, Valencia (Spain)
}

\section{Contact information for Corresponding Author}

Full name: Neus Bernat

Mailing address:

Instituto de Ingeniería de Alimentos para el Desarrollo.

Universitat Politècnica de València. Edificio 8E. Planta 3.

Camino de vera s/n

46022 Valencia (Spain)

e-mail address: neuberpe@upvnet.upv.es

Tel.: (+34) 963877056 


\begin{abstract}
Functional advantages of probiotics combined with interesting composition of oat were considered an alternative to dairy products. In this study, fermentation of oat milk with Lactobacillus reuteri and Streptococcus thermophilus was analysed to develop a new probiotic product. Central Composite Design with Response Surface methodology was used to analyse the effect of different growth factors (glucose, fructose, inulin and starters) on the probiotic population in the product. Optimised formulation was characterised throughout storage time at $4{ }^{\circ} \mathrm{C}$ in terms of $\mathrm{pH}$, acidity, $\beta$-glucan and oligosaccharides contents, colour, rheological behaviour and sensorial evaluation. All formulations studied were adequate to produce fermented foods and minimum dose of each factor was considered as optimum. The selected formulation allowed starters survival above $10^{7} \mathrm{cfu} \mathrm{mL}^{-1}$ to be considered as a functional food and was maintained during the 28 days controlled. $\beta$-glucans remained in the final product with a positive effect on viscosity. Therefore, a new probiotic non-dairy milk was successfully developed with a shelf-life, in terms of sensorial acceptance, slightly shorter than that of standard yoghurts.
\end{abstract}

Key words: fermented oat milk, probiotic, prebiotic, Response surface methodology, formula optimisation.

Abbreviations: CCD, Central Composite design; CLSM, Confocal laser scanning microscopy; RSM, Response Surface Methodology; TA, Titratable acidity. 


\section{Introduction}

Probiotics are defined as "live microorganisms that when administered in adequate amounts confer a health benefit on the host” (FAO/WHO, 2001). Lactobacillus and Bifidobacterium genus are mostly recognised within this group, although Lactococcus, Enterococcus, Saccharomyces and Propianobacterium genus are currently being investigated (Rivera-Espinoza and Gallardo-Navarro, 2010). However, strains are not classified as probiotic unless they accomplish several requirements, such as total safety for the host, resistance to gastric acidity and pancreatic secretions, adhesion to epithelial cells, antimicrobial activity, inhibition of adhesion of pathogenic bacteria, stimulation of immune system and metabolic activity, evaluation of resistance to antibiotics, tolerance to food additives, technological procedures and stability in the food matrix (Prado et. al, 2008).

The use of probiotics in food product manufacturing dates back to the ancient world, although the purposes have changed over time. Nowadays, not only are probiotic microorganisms used for food preserving and organoleptical improvements but also to enhance the nutritional and health benefits: reduction of hypercholesterolemia, host immune modulation, prevention of urogenital diseases, alleviation of constipation, protection against traveler’s diarrhea, protection against colon and bladder cancer, prevention of osteoporosis and food allergies, among other aspects (Lourens-Hattingh and Viljoen, 2001). Nevertheless, host benefits are subject to the strain type used in product manufacture (Sharareh et al., 2009). Although there is no legal definition of the term “probiotic”, different probiotic's dosage recommendations can be found. According to different authors, the minimum number of viable probiotic bacteria should be $10^{7}-10^{9}$ colony forming units (cfu)/g or $\mathrm{mL}$ of a product at the time of consumption and, as to exert healthy effects, it should be consumed daily (Gomes and Malcata, 1999; Stanton et al., 2003; Van Niel et al., 2002) . These recommendations are in compliance with the minimum requirements for standard milk fermented products by the International Dairy Federation and the Japan and EU Associations of Fermented Milks, which is $10^{7} \mathrm{cfu} / \mathrm{g}$ or $\mathrm{mL}$ of starter (Sanz and Dalmau, 2008).

Due to their health properties, there has been a notable increase in the consumption of food products containing probiotic microorganisms. As Granato et al. (2010) reported, the consumption of probiotic products increased by around 13\% and 18\% between 2002 and 2007 in Eastern and Western Europe, respectively. Those products have been traditionally produced by using animal milk, yoghurt being the best known. Nonetheless, new food matrices have been investigated, such as meat, baby food, ice-creams, juices and cereals (Granato et al., 2010) to produce probiotic products. In this sense, several beverages obtained 
from soy, rice, wheat and maize would have huge market potential due to the current consumer demand for cow-milk substitute products (Mårtensson et al., 2000). Those consumers are principally vegetarians, people allergic to animal proteins or lactose intolerant. In this sense, oat milks can be alternative matrices with which to elaborate probiotic products, adding the nutritional and functional characteristics of this cereal, such as the high content in soluble and non-soluble fiber which makes oats a useful product to use in the prevention of different diseases, especially those affecting the colon (Sadiq-Butt et al., 2008). Several studies have shown that $\beta$-glucans, the most prevalent oat soluble fiber, have probiotic activity, while they decrease the blood-cholesterol levels, cardiovascular disorders and improve the lipid and glucose metabolism. Prebiotics are non-digestible components of functional foods that stimulate the proliferation and activity of bacterial populations desirable in the colon and inhibit pathogen multiplication; hence acting beneficially on the host (Mattila-Sandholm et al., 2002; Roberfroid, 2000). $\beta$-glucans are able to stimulate the intestinal microflora, with a particular effect on lactic acid bacteria and Bifidobacteria genus (Angelov et al., 2006).

Regardless of the health benefits of oat consumption, its sensorial properties lead to low consumer acceptance. Nevertheless, both technological and fermentative processes are bound to improve sensorial quality, as well as providing health and nutritional benefits due to the combination of both probiotic and prebiotic compounds, the so-called symbiotics. Previous studies demonstrated that the fermentation step with the mixed culture of $L$. reuteri and $S$. thermophilus required less than 6 hours and that the addition of S. thermophilus led to an improvement in organoleptic properties, mainly flavour. Mårtensson et al. (2001) also observed that the use of mixed culture containing S. thermophilus, L. acidophilus and Bifidobacterium spp. gave a balanced sour taste and a fresh aroma to oat milks, similar to the typical yoghurt flavour.

The aim of the present study was to evaluate the fermentative process of oat milks (Avena Sativa L.) with the mixed culture L. reuteri ATCC 55730 and S. thermophilus CECT 986 (1:1) and the quality of the fermented product. To this end, the effect of different factors, such as the added amount of glucose, fructose, inulin and inoculum, was analysed to ensure there was enough viable probiotic strain (L. reuteri) in the final product. The most adequate fermented formulation was characterised as to its main physicochemical properties and quality parameters (sensorial analysis) in order to determine the product shelf-life.

\section{MATERIALS \& METHODS}




\section{Preparation of oat milk}

Oat milk was produced by soaking and grinding peeled oat (Avena Sativa L.), supplied by Salud e Imaginación S.L. (Masquefa, Barcelona, Spain). The oat:water ratio was 8:100 (w/v), which ensures enough quantity of $\beta$-glucan (oat prebiotic compound) for the subsequent fermentative process (Angelov et al., 2006). The extraction was carried out in Starsoja (Farmanutrients Labs, S.L.; Barcelona, Spain), equipment specifically designed for the production of vegetable milks. To obtain the oat milk, three grinding cycles were used at $90{ }^{\circ} \mathrm{C}$ for 20 minutes. The liquid obtained was then homogenised in a rotor-stator homogenizer (Ultraturrax T25, Janke and Kunkel, Germany) for 3 min at 13,500 rpm and, finally, sterilised at $121^{\circ} \mathrm{C}$ for 15 minutes (Presoclave II, JP-Selecta; Barcelona, Spain).

\subsection{Preparation of fermented products}

\subsubsection{Inoculum preparation}

Lactobacillus reuteri ATCC 55730 and Streptococcus thermophilus CECT 986 were activated from their frozen forms (stored in $40 \mathrm{~g} / 100 \mathrm{~mL}$ glycerol at $-80^{\circ} \mathrm{C}$ ), by transferring each one to its selective broth until optimal bacterial growth is assured. Selective broths were MRS (Scharlab; Barcelona, Spain) for the probiotic Lactobacillus and M17 (DifcoTM; New Jersey; USA) for S. thermophilus. Incubation conditions were $37^{\circ} \mathrm{C} / 24 \mathrm{~h} /$ anaerobically for $L$. reuteri and $42{ }^{\circ} \mathrm{C} / 24 \mathrm{~h} /$ aerobically for $S$. thermophilus.

Likewise, strains were independently incubated in their broths for $24 \mathrm{~h}$ and then centrifuged at 10,000 rpm$10 \mathrm{~min}$ at $4{ }^{\circ} \mathrm{C}$; supernatant was discarded. Immediately after, bacteria were resuspended in PBS-1x buffer (10 mM phosphate, $137 \mathrm{mM} \mathrm{NaCl}, 2.7 \mathrm{mM} \mathrm{KCl,} \mathrm{pH} \mathrm{7.4)} \mathrm{until} \mathrm{they} \mathrm{reached} \mathrm{concentrations} \mathrm{of} 10^{8} \mathrm{cfu} / \mathrm{mL}$.

\subsubsection{Experimental design for fermentation process}

Amount of glucose, fructose, inulin and starter inoculum were selected as growth factors (4 independent variables) to obtain fermented oat milks. Central Composite Design (CCD) with randomised Response Surface methodology (RSM) was used to analyse the effect of the different growth factor combinations on the total count of probiotic bacteria (response variable) and then optimize fermentation process, such as described by other authors (Chen et al., 2004; Cruz et al., 2010; Gupta et al., 2010; Liew et al., 2005; Stepheine et al., 2007; Yaakob et al., 2012). Statistical analysis of the data was carried out in Statgraphics ${ }^{\circledR}$ Centurion XVI by using a orthogonal $2^{4}+$ star design, which studied the effects of the 4 
factors in 31 runs. Factors and levels were chosen taking into account previous studies into oat fermentation studies (Angelov et al. 2006, Sumangala et al., 2005): Glucose: 1 to 2 g/100 mL, Fructose: 1 to 2 g/100 mL, Inulin: 0.7 to $1.3 \mathrm{~g} / 100 \mathrm{~mL}$ and Inoculum: 3 to $4.5 \mathrm{~mL} / 100 \mathrm{~mL}$. The response variable was the probiotic population at the end of fermentation process.

Fermentation process in the 31 runs was carried out by adding the corresponding amount of starter culture (prepared by mixing in a 1:1volume ratio the L. reuteri and S. thermophilus PBS buffer suspensions) to the formulated and sterilised oat milks and then incubating at $40{ }^{\circ} \mathrm{C}$, which was the optimal growth temperature of the mixed culture, according to a preliminary study (data not shown). Fermentation process was stopped when $\mathrm{pH}$ of samples reached 4.4-4.6, by cooling the samples at $4{ }^{\circ} \mathrm{C}$, which was the storage temperature until the analyses were done.

A step-wise second grade polynomial fitting was used to model the response variable as a function of the growth factors.

Optimal formulation of the fermented product was established on the basis of the obtained results for the response variable.

\subsection{Product characterisation}

Newly obtained oat milk and optimal formulation of fermented product stored at different times, were characterised as to content in different sugars and $\beta$-glucan (prebiotic), $\mathrm{pH}$, acidity, density, colour, rheological behaviour and microstructure. In oat milk, dry matter, protein, lipid and ash contents were also analysed. In fermented product, the starter survival throughout storage time (1, 7, 14, 21 and 28 days) at 4 ${ }^{\circ} \mathrm{C}$ was analysed, as well as the sensory attributes. All the analyses were done in triplicate.

\subsubsection{Chemical analyses}

AOAC Official Methods of Analysis were used to determine moisture (AOAC 16.006), total nitrogen (AOAC 958.48) and fat contents (AOAC 945.16) (Horwitz, 2000). Ashes were obtained following the protocol reported by Matissek et al. (1998).

Total $\beta$-glucan content was determined enzymatically with a mixed-linkage $\beta$-glucan detection assay kit (Megazyme TM International Ltd., Wicklow, Ireland).

Sugar profiles were analysed and the different sugars were quantified using the following HPAC-PAD equipment: Metrohm 838 Advanced Sample Processor (Metrohm ${ }^{\circledR}$ Ltd., Herisau Switzerland) in an 
Advanced Compact IC 861 ion chromatograph (IC) equipped with a pulsed amperometric detector to monitor the separation (Bioscan 817). Prior to the analysis, samples were diluted 1:100 with nanopure water. Sample proteins were removed by precipitation with glacial acetic acid and centrifugation at 10,000 rpm for $10 \mathrm{~min}$; pH was then reconstituted at initial values. Before injecting samples into the equipment, they were filtered through nylon membranes $(0.45 \mu \mathrm{m})$. A Metrosep CARB guard column $(5 \times 4.0 \mathrm{~mm}$ Metrohm) and a Metrosep CARB 1 (250x4.6 mm Metrohm) analyses column were used. $20 \mu \mathrm{L}$ of sample was injected and eluted (1 mL/min) with $\mathrm{NaOH} 0.1 \mathrm{M}$, at $32{ }^{\circ} \mathrm{C}$. An Au working electrode was used and applied potentials were $+0.05 \mathrm{~V}$ (between $0-0.40 \mathrm{~s}$ ) $+0.75 \mathrm{~V}$ (between $0.41-0.60 \mathrm{~s}$ ) and $+0.15 \mathrm{~V}$ (between 0.61 - 1 s). Software ICNet 2.3 (Metrohm ${ }^{\circledR}$ Ltd.) was used for data collection and processing. The concentration of each sugar was determined from their respective calibration curves, obtained from standard solutions of mannitol, glucose, fructose and sucrose (Sigma-Adrich ${ }^{\circledR}$, Spain), obtained in triplicate.

\subsection{2 pH, density ( $\rho)$ and tritratable acidity (TA)}

Measurements of $\mathrm{pH}$ and $\rho$ were carried out at $25^{\circ} \mathrm{C}$ using a pH-meter (GLP 21+, Crison Instruments S.A.; Barcelona, Spain) and a picnometer Gay-Lussac, respectively. AOAC standard method was used to determine TA of samples (AOAC 947.05), expressing results as g/100 mL of lactic acid (Horwitz, 2000).

\subsubsection{Rheological behaviour}

The rheological behaviour was characterised in a rotational rheometer (HAAKE Rheostress 1, Thermo Electric Corporation; Germany) with a sensor system of coaxial cylinders type Z34DIN Ti. The shear stress

$(\sigma)$ was measured as a function of shear rate $(\dot{\gamma})$ from 0 to $112 \mathrm{~s}^{-1}$, using 1 minute to reach the maximum shear rate and another minute to attain zero shear rate. Non-linear model (Eq. 1) was applied to determine the flow behavior index $(\mathrm{n})$, consistency index $(\mathrm{K})$ and yield stress $\left(\sigma_{\mathrm{y}}\right)$. Apparent viscosities were calculated at $50 \mathrm{~s}^{-1}$ (Eq. 2), since shear rates generated in mouth when food is being chewed and swallowed are between 10 and $100 \mathrm{~s}^{-1}$ (McClements, 2004).

$$
\begin{gathered}
\sigma=\sigma_{y}+K \dot{\gamma}^{n} \\
\eta=K \cdot \dot{\gamma}^{n-1}
\end{gathered}
$$




\subsubsection{Colour parameters}

Colour coordinates were measured from the reflection spectrum in a Spectrum-colorimeter CM-3600 d (MINOLTA Co; Osaka, Japan). A 20 mm depth cell was used. CIE L ${ }^{*}{ }^{*}$ b coordinates were obtained using illuminant D65/10 observer. Lightness $\left(\mathrm{L}^{*}\right)$, chrome $\left(\mathrm{C}^{*}{ }_{\mathrm{ab}}\right)$ and hue $\left(\mathrm{h}^{*}{ }_{\mathrm{ab}}\right)$ of the different samples as well as colour difference $(\Delta \mathrm{E})$ (equations 3 to 5 ) with respect to the non-fermented sample were obtained.

$$
\begin{array}{r}
C^{*}{ }_{a b}=\sqrt{a^{* 2}+b^{* 2}} \\
h^{*}{ }_{a b}=\operatorname{arctg} \frac{b^{*}}{a^{*}} \\
\Delta E=\sqrt{\left(\Delta L^{*}\right)^{2}+\left(\Delta a^{*}\right)^{2}+\left(\Delta b^{*}\right)^{2}}
\end{array}
$$

\subsubsection{Confocal laser scanning microscopy (CLSM)}

A Nikon confocal microscope C1 unit, which was fitted on a Nikon Eclipse E800 microscope (Nikon, Tokyo, Japan), was used. An Ar laser line (488 nm) was employed as light source to excite fluorescent dyes Rhodamine B and Nile Red. Rhodamine B (Fluka, Sigma-Aldrich, Missouri, USA) with $\lambda$ ex max 488 nm and $\lambda$ em max $580 \mathrm{~nm}$ was dissolved in distilled water at $0.2 \mathrm{~g} / 100 \mathrm{~mL}$. This dye was used to stain proteins and carbohydrates. Nile Red (Fluka, Sigma-Aldrich, Missouri, USA) with $\lambda$ ex max $488 \mathrm{~nm}$ and $\lambda$ em max $515 \mathrm{~nm}$ was dissolved in PEG 200 at $0.1 \mathrm{~g} / \mathrm{L}$. This dye was used to stain fat. An oil immersion objective lens (60x/1.40NA/Oil/ Plan Apo VC Nikon) was used.

For sample visualisation a microscopy slide was elaborated with two razor blades (platinum coated double edge blades with $0.1 \mathrm{~mm}$ thickness) stuck to a glass. $20 \mu \mathrm{L}$ of the sample were placed on the microscope slide, within the central gap of the blades; $10 \mu \mathrm{L}$ of Rhodamine B solution and $10 \mu \mathrm{L}$ of Nile Red solution were added and the cover slide was carefully positioned. Observations were performed 10 min after diffusion of the dyes into the sample. Images were observed and stored with 1,024 x 1,024 pixel resolution, using the microscope software (EZ-C1 v.3.40, Nikon, Tokyo, Japan).

\subsubsection{Starter survival}

Counts of $L$. reuteri and $S$. thermophilus were performed using pour plate technique, according to the method described by the International Dairy Federation (International IDF standards, 1997). Acidified MRS agar (Scharlab; Barcelona, Spain) selective media was used for L. reuteri and M17 agar (Difco ${ }^{\mathrm{TM}}$; New 
Jersey; USA) for $S$. thermophilus. Incubation conditions were $37^{\circ} \mathrm{C}$ for $48 \mathrm{~h}$ in aerobic conditions for $S$. thermophilus and $37^{\circ} \mathrm{C}$ for $24 \mathrm{~h}$ in anaerobic conditions for L. reuteri.

\subsection{Statistical Analysis}

Results were analysed by multifactor analysis of variance with $95 \%$ significance level using Statgraphics ${ }^{\circledR}$ Centurion XVI. Multiple comparisons were performed through 95\% LSD intervals.

\section{RESULTS AND DISCUSSION}

\subsection{Characterisation of the oat milk: chemical composition and microstructure}

Results in oat milk chemical composition were: $6.5 \pm 0.3 \mathrm{~g} / 100 \mathrm{~mL}$ of dry matter, $0.65 \pm 0.03 \mathrm{~g} / 100 \mathrm{~mL}$ of proteins, $0.241 \pm 0.004 \mathrm{~g} / 100 \mathrm{~mL}$ of $\beta$-glucan, $0.094 \pm 0.003 \mathrm{~g} / 100 \mathrm{~mL}$ of fats, $0.099 \pm 0.005 \mathrm{~g} / 100 \mathrm{~mL}$ of ashes and $0.047 \pm 0.007 \mathrm{~g} / 100 \mathrm{~mL}$ of total sugars, the latter obtained from the sum of all the individual sugars analysed. These compositional values are in agreement with those reported by other authors (Sadiq-Butt et al., 2008). As was observed during the extraction process, the major losses of oat components occur in the fibre and lipid fractions, which remained in the waste by-product during the extraction process. This fact is coherent with that observed in the oat milk microstructure, by using the confocal technique (Figure 1), where the presence of a small amount of lipid droplets, yellow-green in colour, can be observed. Proteins and carbohydrates appear red-coloured, together with some cellular fragments. As confocal pictures show, the oat milk's microstructure is organised as a polysaccharide network (PM) where fat and protein are embedded. This arrangement is associated to the gelling properties of $\beta$-glucans, once is heated (Lazaridou and Biliaderis, 2009). Moreover, almost all the lipid droplets are retained in the polysaccharide-protein matrix which is responsible for the physical stability of the oat milk, even after the sterilisation treatment. It was observed that some proteins were attached to fat globules, thus providing protection against the socalled Ostwald ripening or other destabilisation processes in emulsions. 

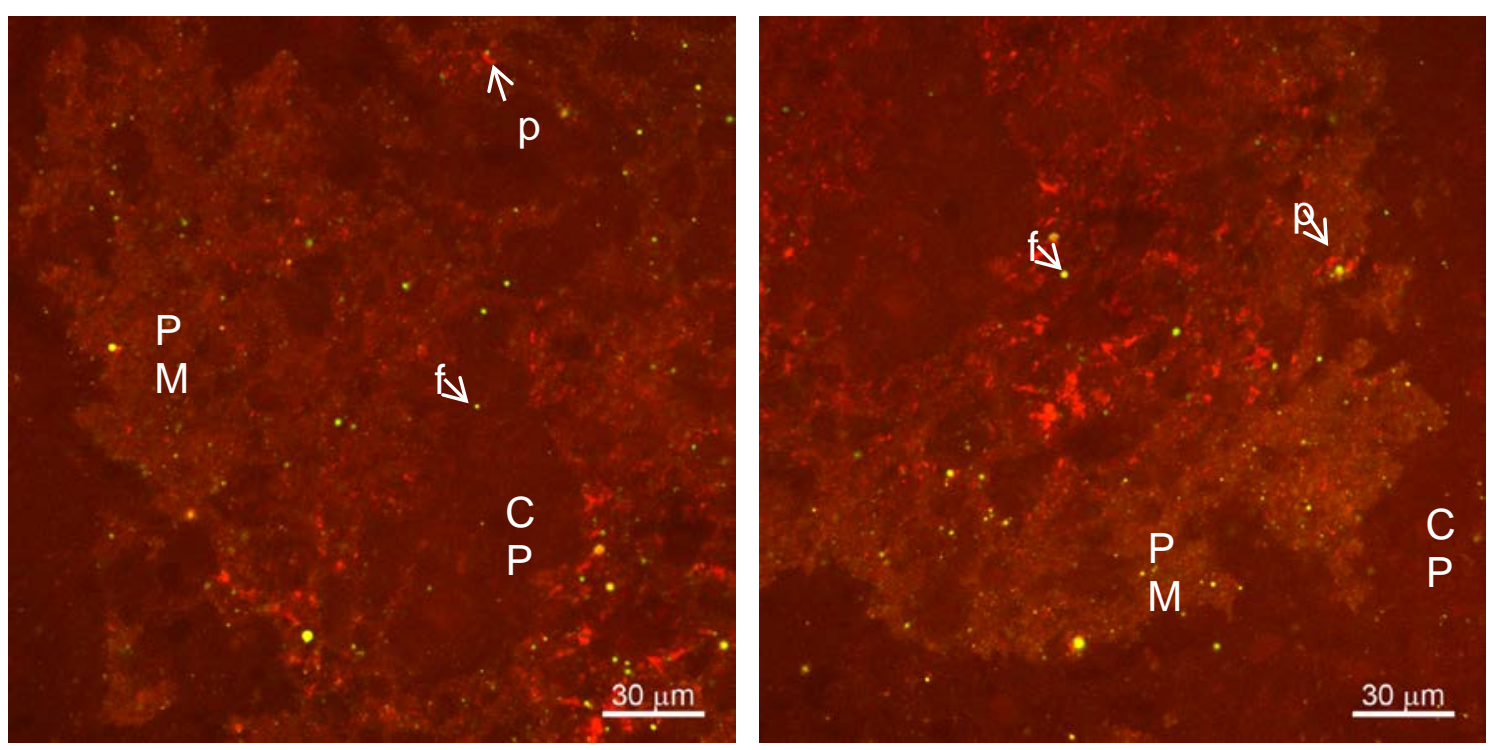

Figure 1. Confocal pictures of sterilised oat milk, where fat component appears yellow-green in color, proteins are vivid red in color and carbohydrates are dull red in color. PM: Polysaccharide-protein matrix, CP: Continuous phase, f: fat droplet, p: protein.

\subsection{Effect of growing factors on fermentation process}

Table 1 shows the experimental values of the $L$. reuteri counts (log cfu/mL) obtained for each run of the CCD. All the formulations permitted the development of probiotic oat fermented milk, since their response variables were over $7 \log \mathrm{cfu} / \mathrm{mL}$, which is within the probiotic amount recommended to ensure health effects in consumers (Gomes and Malcata, 1999; Stanton et al., 2003; Van Niel et al., 2002)

Table 1. Total counts of $L$. reuteri obtained in the different fermented products corresponding to the experimental design, as a function of the levels of the growing factors.

\begin{tabular}{ccccc|c}
\hline & \multicolumn{3}{c|}{ GROWING FACTORS } & RESPONSE \\
Run order & \multicolumn{7}{c}{} & & VARIABLE \\
\cline { 2 - 6 } & $\mathbf{X}_{\mathbf{1}}$ & $\mathbf{X}_{2}$ & $\mathbf{X}_{3}$ & $\mathbf{X}_{4}$ & $\mathbf{Y}$ \\
\hline $\mathbf{1}$ & 0 & $+\alpha$ & 0 & 0 & 8.04 \\
$\mathbf{2}$ & 0 & 0 & $+\alpha$ & 0 & 8.23 \\
$\mathbf{3}$ & -1 & +1 & -1 & +1 & 8.04 \\
$\mathbf{5}$ & 0 & 0 & 0 & 0 & 8.26 \\
& +1 & +1 & -1 & +1 & 9.00
\end{tabular}




\begin{tabular}{|c|c|c|c|c|c|}
\hline 6 & 0 & 0 & 0 & 0 & 8.08 \\
\hline 7 & 0 & 0 & 0 & 0 & 8.36 \\
\hline 8 & $-\alpha$ & 0 & 0 & 0 & 9.15 \\
\hline 9 & -1 & +1 & +1 & +1 & 8.73 \\
\hline 10 & -1 & +1 & -1 & -1 & 9.20 \\
\hline 11 & +1 & -1 & -1 & +1 & 8.95 \\
\hline 12 & +1 & -1 & +1 & -1 & 7.46 \\
\hline 13 & 0 & 0 & 0 & 0 & 9.34 \\
\hline 14 & $+\alpha$ & 0 & 0 & 0 & 10.25 \\
\hline 15 & -1 & -1 & +1 & -1 & 8.81 \\
\hline 16 & +1 & +1 & +1 & -1 & 9.60 \\
\hline 17 & +1 & -1 & -1 & -1 & 8.76 \\
\hline 18 & 0 & 0 & 0 & 0 & 9.20 \\
\hline 19 & 0 & 0 & $-\alpha$ & 0 & 9.34 \\
\hline 20 & +1 & +1 & +1 & +1 & 9.28 \\
\hline 21 & 0 & 0 & 0 & $+\alpha$ & 8.67 \\
\hline 22 & -1 & +1 & +1 & -1 & 9.11 \\
\hline 23 & 0 & $-\alpha$ & 0 & 0 & 9.46 \\
\hline 24 & -1 & -1 & -1 & +1 & 9.28 \\
\hline 25 & +1 & -1 & +1 & +1 & 8.21 \\
\hline 26 & 0 & 0 & 0 & 0 & 8.08 \\
\hline 27 & 0 & 0 & 0 & 0 & 8.26 \\
\hline 28 & +1 & +1 & -1 & -1 & 8.32 \\
\hline 29 & 0 & 0 & 0 & $-\alpha$ & 8.54 \\
\hline 30 & -1 & -1 & -1 & -1 & 9.83 \\
\hline 31 & -1 & -1 & +1 & +1 & 8.15 \\
\hline
\end{tabular}

*Factors $\mathrm{X}_{1}, \mathrm{X}_{2}, \mathrm{X}_{3}, \mathrm{X}_{4}$ and $\mathrm{Y}$ stand for Glucose: 1-2 g/100 mL; Fructose: 1-2 g/100 mL; Inulin: 0.7-1.3 g/100 mL; Inoculum: 3-4.5 mL/100 mL; Probiotic counts (log cfu/mL), respectively. 
Results from the 31 runs were fitted to a second order polynomial equation and the removal of nonsignificant terms ( $>$ > 0.05) was applied, except when the elimination of such terms decreased the explained variance ( $\mathrm{R}^{2}$ adj). The goodness of the fitted model was evaluated through an analysis of variance, mainly based on the F-test and on the $\mathrm{R}^{2}$ adj, which provide a measurement of how much of the variability in the observed response values could be explained by the experimental factors and their interactions (Granato et al. 2010). Table 2 summarizes the estimated regression coefficients of the second order model obtained, in which fit parameters from the analysis of variance are included.

Table 2. Regression coefficients and analysis of variance for probiotic counts $(\log \mathrm{cfu} / \mathrm{mL})$ obtained from the fitted model.

\begin{tabular}{|c|c|}
\hline Factor/ Parameter & Regression coefficient / Value \\
\hline Constant & 22.18 \\
\hline Glucose & -8.22 \\
\hline Fructose & -3.81 \\
\hline Inulin & -4.11 \\
\hline Inoculum & -1.14 \\
\hline Glucose x Glucose & 1.25 \\
\hline Glucose x Fructose & 0.95 \\
\hline Glucose x Inoculum & 0.76 \\
\hline Fructose $x$ Inulin & 2.38 \\
\hline P-value Lack-of-fit & 0.880 \\
\hline $\mathrm{R}^{2}$ & 0.59 \\
\hline $\mathrm{R}^{2}$-adj & 0.51 \\
\hline Standard error of est. & 0.53 \\
\hline Mean absolute error & 0.32 \\
\hline Durbin-Watson statistic (P-value) & $1.678(0.218)$ \\
\hline
\end{tabular}

$\mathbf{R}^{2}=$ coefficient of determination $\mathbf{R}^{2}$-adj = explained variance 
As can be seen in the coefficients (Table 2), when the growth factors appear as linear variables, they seem to negatively affect the total probiotic counts. Nevertheless, a more thorough examination of the fitted model indicated that all the coefficients corresponding to factor interactions (second order terms) were positive in value, which explains the overall positive impact of the increasing levels of glucose, fructose, inulin and starter inoculums on the total probiotic counts. These results indicated that the individual factors were not truly independent of one another, which is statistically known as "multicolinearity" and represents a common problem in regression analyses (Bender et al., 1989). When multicolinearity occurs, the elimination of non-significant explanatory variables in the model is not recommended (Bender et al., 1989).

As regards the model fit, the lack-of-fit parameter was not significant $(\mathrm{p}>0.05)$ and the P-value of the Durbin-Watson statistic was greater than 0.05, meaning that there is no indication of serial autocorrelation in the residuals at the 5\% significance level. Both parameters indicated that the obtained model is adequate for predicting probiotic survival in oat milk. In practice, a model is considered adequate to describe the influence of the variable(s) when the coefficient of determination $\left(\mathrm{R}^{2}\right)$ is at least $80 \%$ (Yaakob et al. 2012) or the values of $\mathrm{R}^{2}$ adj over 70\% (Cruz et al. 2010). The obtained model explained only $51 \%$ of the variation in the experimental data ( $\mathrm{R}^{2}$ adj) (Table 2), which is partially explained by the narrow range of experimental response variable $(\approx 2.5 \log \mathrm{cfu} / \mathrm{mL})$. The narrow variation in response variable made it difficult to obtain greater $\mathrm{R}^{2}$ adj values. Therefore, the obtained prediction model should only be used to make rough predictions.

Figure 2 shows the Response Surface plots for the L. reuteri counts. 4 different plots were obtained in each of which one of the factors was fixed at the smallest value. As deduced from Table 1, surfaces showed that many formulations could be used for the production of probiotic fermented oat milk, by considering the minimum recommended strain survival ( $\geq 10^{7} \mathrm{cfu} / \mathrm{mL}$ ). Taking these results into account, a possible optimum formulation should be defined as one that has the minimum production costs. In this sense, the formulation considered as optimum was the one to which the smallest amount of ingredients was added. This optimum corresponds to the formulation where $0.65 \mathrm{~g} / 100 \mathrm{~mL}$ of glucose, $0.65 \mathrm{~g} / 100 \mathrm{~mL}$ of fructose, $0.4 \mathrm{~g} / 100 \mathrm{~mL}$ of inulin and $3 \mathrm{~mL} / 100 \mathrm{~mL}$ of mixed culture inoculum was incorporated into the oat milk.

This optimal formulation was submitted to fermentation process and data were analysed in order to validate the prediction model. Results showed that the fermented product reached $4.37 \pm 0.02$ value of $\mathrm{pH}$ in $3.5 \mathrm{~h}$ at $40{ }^{\circ} \mathrm{C}$ with a L. reuteri survival of around $9 \log \mathrm{cfu} / \mathrm{mL}$. Other oat fermentation studies made 
with $L$. reuteri showed longer fermentation times $(16 \mathrm{~h})$ and lower probiotic survivals, which were 8 log $\mathrm{cfu} / \mathrm{mL}$ when it was the only starter and one log less when it was combined with typical yoghurt starter bacteria (Mårtensson et al., 2002).
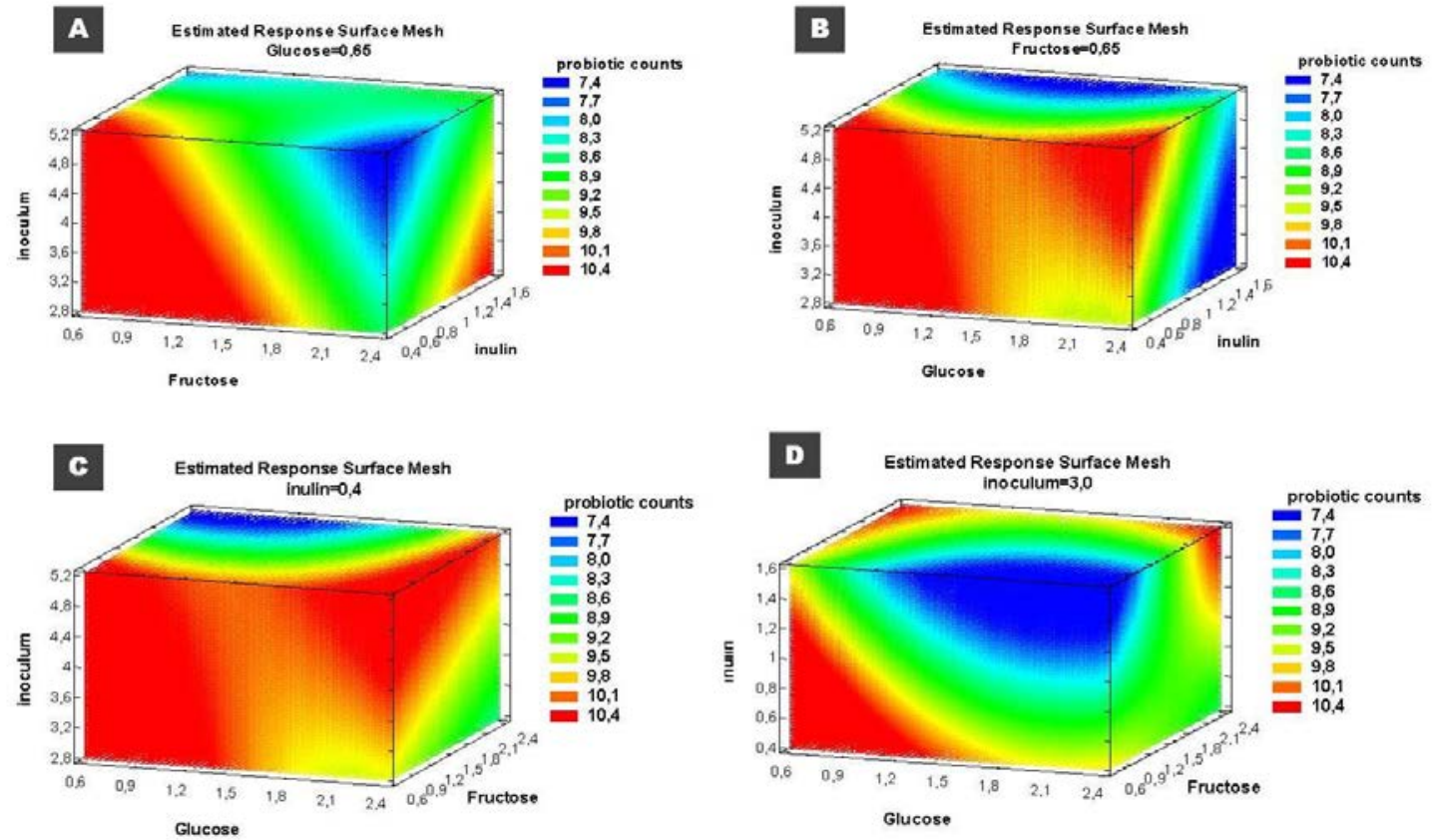

Figure 2. Response Surface plots of the effect of the different growth factors (glucose, fructose, inulin and starters inoculum) on the viability of L. reuteri (expressed in log cfu/mL). Plots were obtained by keeping the level of one factor constant.

\subsection{Properties of oat fermented product}

\subsubsection{Bacterial counts and acid production}

Average values of $\mathrm{pH}$ and Titratable Acidity (TA) in fermented oat milk vs. storage time are summarised in Table 3. This table also includes bacterial counts values of L. reuteri and S. thermophilus (log cfu/mL) throughout storage time.

Initial acidity of the oat fermented milk averaged $1.7 \mathrm{~g} / 100 \mathrm{~mL}$ of lactic acid. This value is higher than in standard yoghurt, in which it is around 0.8-1 g/100 mL of lactic acid (Mistry and Hassan, 1992; Tamime and Robinson, 2000). The high acidity level could be explained considering that, besides the lactic acid 
synthesis, the $L$. reuteri strain has a heterofermentative metabolic pathway which ends in acetic acid synthesis (Årsköld et al., 2008).

Physicochemical properties of oat milk were modified due to fermentation process. $\mathrm{pH}$ of the fermented product remained within the desired ranges (above 4) for the first day but, after 7 days, $\mathrm{pH}$ significantly decreased reaching a unit below the initial value. These changes were expected considering that starters were viable over the entire storage time and, therefore, they were still generating acidic compounds.

Table 3. Values (mean (s.d.)) of pH, Titratable Acidity (TA) and bacterial counts of fermented oat milk throughout storage time at $4{ }^{\circ} \mathrm{C}$. Data of non-fermented oat milk are included for comparisons.

\begin{tabular}{cccc|cc}
\hline Sample & $\begin{array}{c}\text { Storage } \\
\text { time }(\mathrm{d})\end{array}$ & $\mathbf{p H}$ & $\begin{array}{c}\text { TA } \\
(\mathrm{g} / 100 \mathrm{~mL} \text { lactic acid })\end{array}$ & $\begin{array}{c}\text { L. reuteri } \\
(\log \mathrm{cfu} / \mathrm{mL})\end{array}$ & $\begin{array}{c}\text { S. thermophilus } \\
(\log \mathrm{cfu} / \mathrm{mL})\end{array}$ \\
\hline Oat milk & - & $6.41(0.02)$ & $0.53(0.03)$ & - & - \\
\hline & $\mathbf{0}$ & $4.37(0.02)^{\mathrm{a}}$ & $1.7(0.0)^{\mathrm{a}}$ & $8.80(0.03)^{\mathrm{a}}$ & $8.01(0.02)^{\mathrm{a}}$ \\
& $\mathbf{1}$ & $4.08(0.04)^{\mathrm{b}}$ & $2.1(0.2)^{\mathrm{ab}}$ & $8.49(0.11)^{\mathrm{b}}$ & $7.89(0.04)^{\mathrm{b}}$ \\
Fermented & $\mathbf{7}$ & $3.79(0.05)^{\mathrm{c}}$ & $2.5(0.2)^{\mathrm{bc}}$ & $7.72(0.05)^{\mathrm{a}}$ & $7.75(0.03)^{\mathrm{c}}$ \\
oat product & $\mathbf{1 4}$ & $3.65(0.06)^{\mathrm{d}}$ & $2.8(0.3)^{\mathrm{c}}$ & $7.48(0.07)^{\mathrm{c}}$ & $7.43(0.02)^{\mathrm{d}}$ \\
& $\mathbf{2 1}$ & $3.61(0.07)^{\mathrm{d}}$ & $3.7(0.6)^{\mathrm{d}}$ & $7.31(0.14)^{\mathrm{d}}$ & $7.28(0.03)^{\mathrm{e}}$ \\
& $\mathbf{2 8}$ & $3.30(0.05)^{\mathrm{e}}$ & $5.0(0.4)^{\mathrm{e}}$ & $7.43(0.06)^{\mathrm{c}}$ & $7.629(0.015)^{\mathrm{c}}$ \\
\hline
\end{tabular}

a, b, c, d, e Different letters in same column indicates significant differences among samples at different control times (95\% of confidence)

Although the viability of starter bacteria decreased during the storage time, especially in L. reuteri, the minimum survival recommended $\left(10^{7} \mathrm{cfu} / \mathrm{mL}\right)$ was ensured in both strains until the end of the storage (Sanz \& Dalmau, 2008). Results show that both microorganisms are highly resistant to an acidic environment and that the oat formulation contained sufficient nutrients for starter growth during the whole storage time. Previous works have also shown good fermentation results of $L$. reuteri by using oat as culture media (Johansson et al. 1993; Mårtensson et al., 2002).

\subsubsection{Sugar and $\beta$-glucan contents}


The concentration values of these components can provide interesting information about bacterial activity during the product shelf life. Table 4 shows the values of each sugar identified in oat fermented product and their changes throughout the storage time. In Figure 3, typical chromatograms, with the sugar peaks obtained for both non-fermented milk and that fermented for 28 days at $4{ }^{\circ} \mathrm{C}$, are shown.

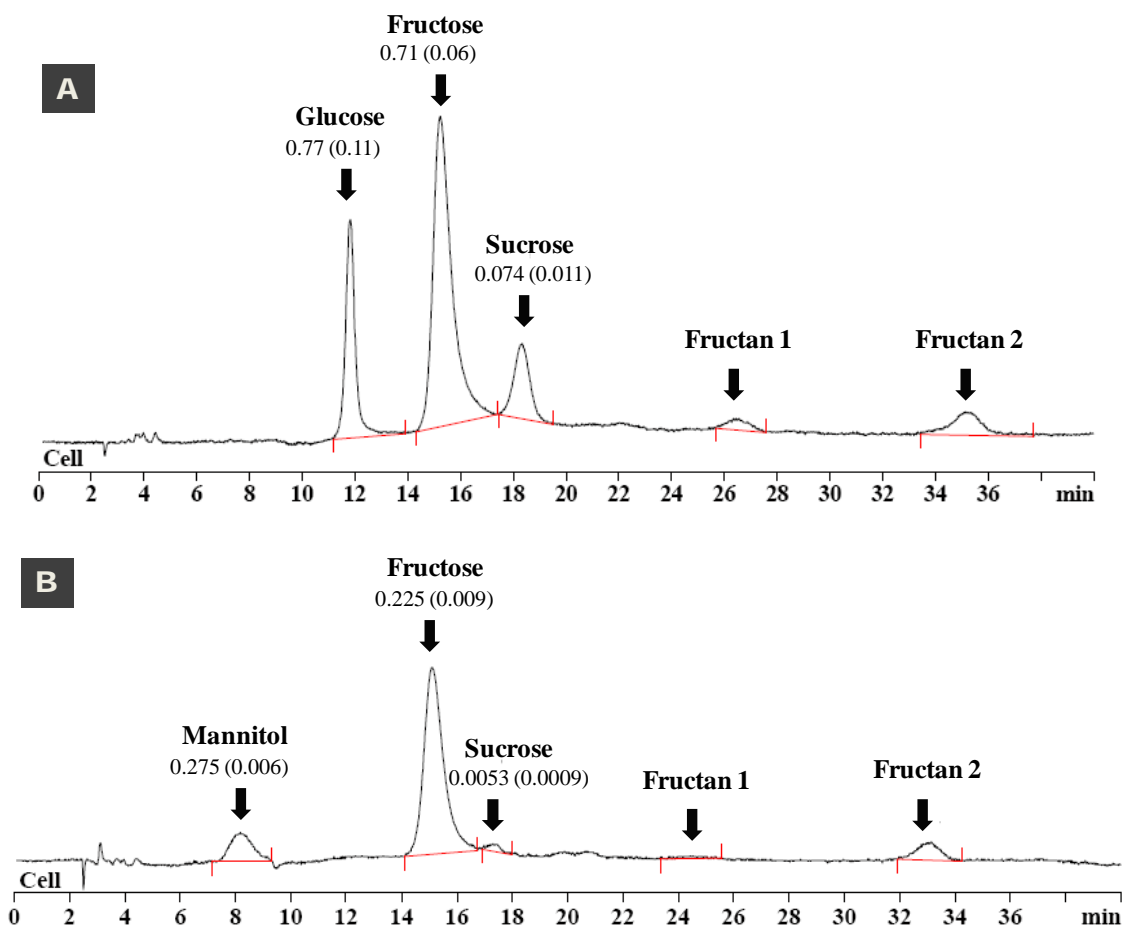

Figure 3. Chromatograms with sugar peaks obtained in HPAC-PAD analysis for oat milk (A) and fermented oat product after 28 days of storage at $4{ }^{\circ} \mathrm{C}(\mathrm{B})$.Sugar concentrations are indicated (mean values in $\mathrm{g} / 100 \mathrm{~mL}$ and (s.d.)).

Prior to the fermentation process, sucrose (from oat), glucose and fructose (added), were present in oat milk. Other sugars (peaks), which could not be identified, could come from the added inulin, taking into account the thermal stability of $\beta$-glucans (Lazaridou and Biliaderis, 2007): They were classified as fructans, which is a term that includes both inulin and its derivatives (Roberfroid, 2005). After the fermentation process, a huge reduction in the contents of initial monosaccharides and sucrose was observed and subsequently, a significant $(\mathrm{p}<0.05)$ decrease, gradual throughout storage time, was observed (Table 4). These results are expected, since bacteria starters were viable during the whole storage period and they consumed sugars as nutrients (Table 3). On the other hand, a new peak appeared in fermented products that was not present in non-fermented milk, which was identified as mannitol. The appearance of this compound 
is attributed to the capacity of L. reuteri to synthesise this sugar (Årsköld et al., 2008), and it could add value to the designed product, since it is seen to have antioxidant properties (Wisselink et al., 2002).

Table 4. Concentrations (mean values and (s.d.)) throughout storage time of the different sugars identified in fermented oat milk. Concentrations of sugars identified in non-fermented oat milk are also included for comparisons.

\begin{tabular}{lccccc}
\hline & $\begin{array}{c}\text { Time stored } \\
(\mathrm{d})\end{array}$ & $\begin{array}{c}\text { Mannitol } \\
(\mathrm{g} / 100 \mathrm{~mL})\end{array}$ & $\begin{array}{c}\text { Glucose } \\
(\mathrm{g} / 100 \mathrm{~mL})\end{array}$ & $\begin{array}{c}\text { Fructose } \\
(\mathrm{g} / 100 \mathrm{~mL})\end{array}$ & $\begin{array}{c}\text { Sucrose } \\
(\mathrm{g} / 100 \mathrm{~mL})\end{array}$ \\
\hline Oat milk & - & - & $0.77(0.11)$ & $0.71(0.06)$ & $0.074(0.011)$ \\
\hline \multirow{2}{*}{ Fermented } & $\mathbf{1}$ & $0.322(0.026)^{\mathrm{a}}$ & $0.116(0.006)^{\mathrm{a}}$ & $0.345(0.024)^{\mathrm{a}}$ & $0.0126(0.0013)^{\mathrm{a}}$ \\
& $\mathbf{7}$ & $0.276(0.019)^{\mathrm{b}}$ & $0.013(0.012)^{\mathrm{b}}$ & $0.34(0.04)^{\mathrm{a}}$ & $0.0100(0.0008)^{\mathrm{b}}$ \\
oat product & $\mathbf{1 4}$ & $0.314(0.029)^{\mathrm{a}}$ & $0(0)^{\mathrm{c}}$ & $0.30(0.03)^{\mathrm{b}}$ & $0.0081(0.0007)^{\mathrm{c}}$ \\
& $\mathbf{2 1}$ & $0.277(0.022)^{\mathrm{b}}$ & $0(0)^{\mathrm{c}}$ & $0.29(0.06)^{\mathrm{b}}$ & $0.0049(0.0007)^{\mathrm{d}}$ \\
& $\mathbf{2 8}$ & $0.275(0.006)^{\mathrm{b}}$ & $0(0)^{\mathrm{c}}$ & $0.225(0.009)^{\mathrm{c}}$ & $0.0053(0.0009)^{\mathrm{d}}$
\end{tabular}

a, b, c, d Different letters in same column indicates significant differences between measurement times (95\% of confidence)

Being a monosaccharide, glucose was a selective nutrient for starter bacteria, since it was the one which decreased most after fermentation. Indeed, this sugar was not present in 14-day fermented products. Surprisingly, fructose did not have the same tendency as glucose, which could be explained by considering that starters might have hydrolysed inulin (unions of fructose) for nutrition purposes. Inulin and its derivatives are seen to be able to stimulate the growth and/or metabolic activity of bacteria, mainly the genus of Bifidobacteria and Lactobacilli (Gibson et al., 2004). This assumption is reinforced by the qualitative analysis of chromatograms, since the concentration of fructan decreased at the end of the storage (Figure 3).

Regarding $\beta$-glucan content (data not shown in figure), oat milk initially contained $0.241 \pm 0.004$ $\mathrm{g} / 100 \mathrm{~g}$. Once the fermentation process ended, the initial concentration significantly $(\mathrm{p}<0.05)$ decreased $\approx 17 \%$, despite the thermal and acidic stability of $\beta$-glucans (Lazaridou and Biliaderis, 2007; Velasco et al., 2009). Therefore, starter bacteria might have hydrolysed this compound in order to obtain nutrients for their growth. Nevertheless, $\beta$-glucan content in fermented products did not change significantly throughout 
storage time, reaching an average value of $0.199 \pm 0.008 \mathrm{~g} / 100 \mathrm{~g}$. Results reflected that the starter bacteria did not have preferences in this polysaccharide and, from the development of the concentration of analysed sugars, they could also use the added inulin for their survival. Nevertheless, this fact is positive for the final product, since $\beta$-glucan prebiotic properties are still available in the product and are beneficial for consumer health.

\subsubsection{Microstructure}

Figure 4 shows pictures of fermented oat milk microstructure obtained in confocal microscope. The main difference initial oat milk microstructure (Figure 1) was the presence of a cloudy red area (S) that could be the starter bacteria. Moreover, much smaller amounts of proteins were observed; the starters might have hydrolysed them so as to obtain aminoacids for their nutrition. Nonetheless, and in spite of having observed some coalesced fat droplets, the major fat component was still integrated in the structure in PM network, which was positive for the product's physical stability.
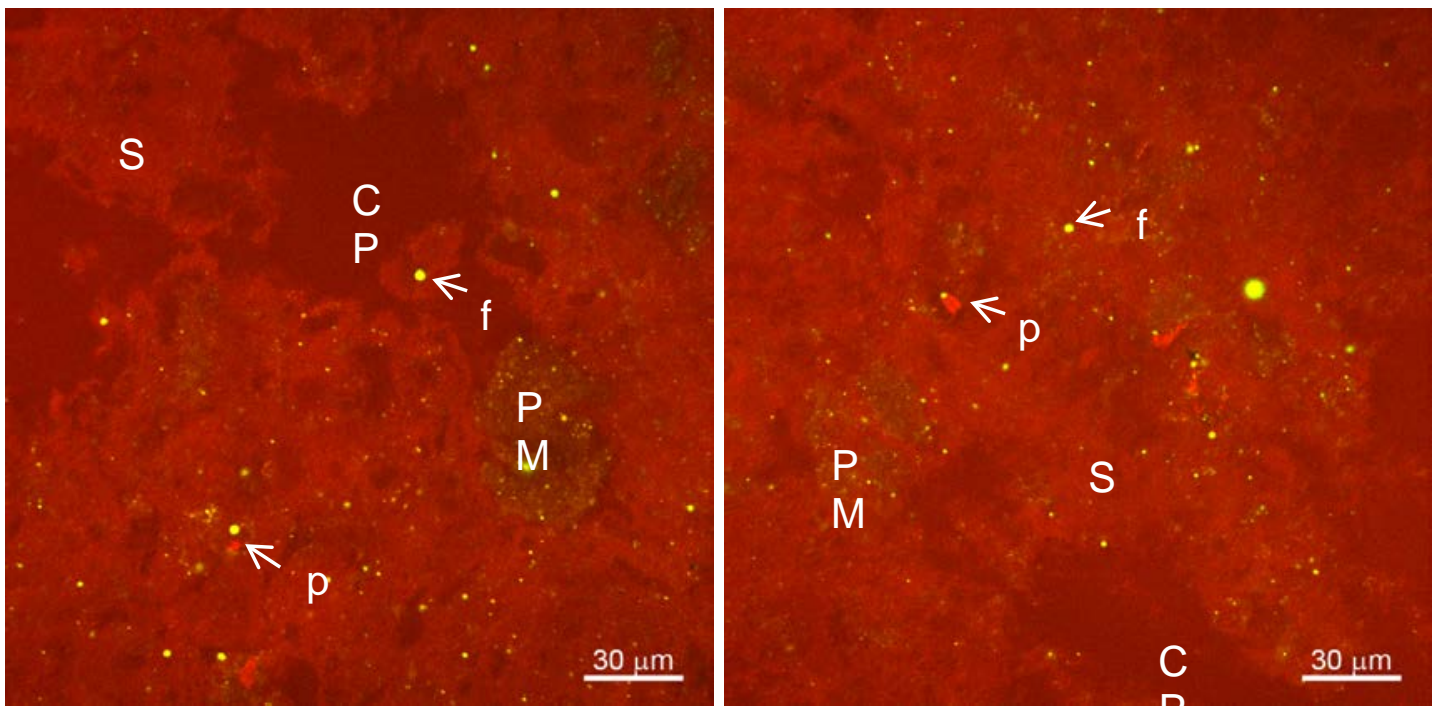

Figure 4 Confocal pictures of fermented oat milk, where the fat component appears yellow-green in colour, proteins appear vivid red in colour and carbohydrates and starter bacteria dull red in colour. PM: Polysaccharide matrix, CP: Continuous phase, S: starter bacteria, f: fat droplet, p: protein

\subsubsection{Physical properties}

No statistical differences were found between the density parameters $(\rho)$ of fermented samples after different storage times, the mean value being $1043 \pm 3 \mathrm{Kg} / \mathrm{m}^{3}$. Nevertheless, fermentation causes a slight 
increase in $\rho$, since values for non-fermented milk were $1019 \pm 9 \mathrm{Kg} / \mathrm{m}^{3}$. Starters could modify the inner structure of oat milks, probably due to their proteolytic activity, inferred both from the analysis of their microstructure (Figure 4) and from possible changes in charge within the product matrix.

Rheological parameters play a key role in the definition of textural and sensorial perception of a new product. These parameters were obtained by using a non-linear regression procedure to fit Eq. 1 to the flow curves of fermented and non-fermented oat milks and are summarised in Table 5. The apparent viscosity of samples at $50 \mathrm{~s}^{-1}$ shear rate was also shown.

Table 5. Mean values and standard deviation of consistency index (K), flow behavior index (n) and yield stress $\left(\sigma_{\mathrm{y}}\right)$ of fermented oat milk, obtained from fitting experimental data to non-linear model (non-linear correlation coefficient $\mathbf{R}^{2}$ is included). Apparent viscosity $(\eta)$ was calculated at shear rate of $50 \mathrm{~s}^{-1}$. Data of oat milk are included for comparisons

\begin{tabular}{|c|c|c|c|c|c|c|}
\hline & $\begin{array}{l}\text { Storage } \\
\text { time (d) }\end{array}$ & $\begin{array}{c}\mathbf{K} \\
\left(\mathrm{Pa} \cdot \mathrm{s}^{\mathrm{n}}\right)\end{array}$ & $\mathbf{n}$ & $\begin{array}{c}\sigma_{\mathbf{y}} \\
(\mathrm{Pa})\end{array}$ & $\mathbf{R}^{2}$ & $\begin{array}{c}\eta_{50} \\
(\mathrm{~Pa} \cdot \mathrm{s})\end{array}$ \\
\hline Oat milk & Oat milk & $0.425(0.013)$ & $0.806(0.006)$ & $4.0(0.2)$ & 0.991 & $0.43 \cdot(0.006)$ \\
\hline \multirow{5}{*}{$\begin{array}{l}\text { Fermented } \\
\text { oat product }\end{array}$} & 1 & $0.70 \cdot(0.04)^{\mathrm{a}}$ & $0.75(0.03)^{\mathrm{a}}$ & $8.8 \cdot(0.7)^{\mathrm{a}}$ & 0.987 & $0.47 \cdot(0.02)^{\mathrm{a}}$ \\
\hline & 7 & $1.042(0.004)^{b}$ & $0.72(0.0)^{\mathrm{abc}}$ & $11(0.0)^{\mathrm{b}}$ & 0.997 & $0.55(0.03)^{b}$ \\
\hline & 14 & $0.74(0.08)^{\mathrm{a}}$ & $0.721(0.022)^{\mathrm{ab}}$ & $11.3(1.4)^{\mathrm{b}}$ & 0.986 & $0.487 \cdot(0.013)^{\mathrm{a}}$ \\
\hline & 21 & $0.85(0.02)^{\mathrm{c}}$ & $0.688(0.007)^{\mathrm{c}}$ & $11.7(0.6)^{\mathrm{b}}$ & 0.979 & $0.494 \cdot(0.008)^{\mathrm{a}}$ \\
\hline & 28 & $0.876(0.098)^{\mathrm{d}}$ & $0.699(0.022)^{\mathrm{bc}}$ & $11.2(1.4)^{\mathrm{b}}$ & 0.979 & $0.50 \cdot(0.02)^{\mathrm{a}}$ \\
\hline
\end{tabular}

a, b, c, d Different letters in same column indicates significant differences between samples analysed (95\% of confidence)

Both fermented and non-fermented oat milks were classified as plastic, since samples showed yield stress and flow behaviour index (n) values $<1$. Other authors also observed shear thinning behaviour in cereal $\beta$-glucan aqueous dispersions (Lazaridou and Biliaderis, 2009; Vasiljevic et al., 2007; Velasco et al., 2009). The fermentation process modified the original rheological behaviour of oat milk $(\mathrm{p}<0.05)$, increasing the apparent viscosity of the samples. This parameter did not show significant changes throughout the storage time $(\mathrm{p}<0.05)$. Although proteins seem to be hydrolysed by the starter bacteria 
(Figure 4$)$ and the fermented samples had a lower $\beta$-glucan concentration than the non-fermented ( $\approx 17 \%$ less), the remaining oat $\beta$-glucans showed a thickening and gelling capacity, which means they have the ability to increase the viscosity of aqueous solutions. Several authors (Lizaridou and Biliaderis, 2009) reported that the lower the molecular weight of the $\beta$-glucan, the greater is its gelling capacity, which can be attributed to the higher mobility of the shorter chains that enhances diffusion and lateral interchain associations. Indeed, Piotrowska et al. (2009) and Sahan et al. (2008) observed that $\beta$-glucan additions to yoghurt production improved sensory properties and physical stability at concentrations of 0.3 and 0.5 $\mathrm{g} / 100 \mathrm{~mL}$. Besides the effect of $\beta$-glucans on the final viscosities of fermented products, $L$. reuteri is able to synthesize exopolysaccharides which might contribute to the observed increase in viscosity (Årsköld, et al., 2007).

Although storage time was not observed to have a significant effect on rheological parameters, a little syneresis was observed after 28 storage days, coherent with the progressive aggregation of the particles forming the dispersed phase.

The colour parameters of the samples are shown in Table 6, in which the mean values and standard deviation of colour coordinates of fermented and non-fermented samples are shown. The different values in fermented samples were not observed to differ significantly $(\mathrm{p}<0.05)$ throughout the storage time, and so the average values of all fermented samples were included in the table.

Table 6 Mean values and (standard deviation) of Lightness $\left(L^{*}\right)$, color coordinates a* and $b^{*}$, hue $\left(h^{*}{ }_{a b}\right)$, chrome $\left(C^{*}{ }_{a b}\right)$ and color difference $(\Delta E)$ between non-fermented and fermented oat milks.

\begin{tabular}{c|ccccc|c}
\hline Sample & $\mathbf{L}^{*}$ & $\mathbf{a}^{*}$ & $\mathbf{b}^{*}$ & $\mathbf{C}^{*}{ }_{\mathrm{ab}}$ & $\mathbf{h}_{\mathbf{a b}}$ & $\Delta \mathbf{E}$ \\
\hline Oat milk & $68.8 \cdot(0.4)$ & $-0.4(0.2)$ & $14.1(0.4)$ & $14.1(0.4)$ & $91.5(1.0)$ & - \\
\hline Fermented & $69.9(0.3)$ & $-0.67(0.05)$ & $13.43(0.25)$ & $13.44(0.25)$ & $92.9(0.3)$ & $1.4(0.2)$ \\
product & & & & & & \\
\hline
\end{tabular}

The structural changes caused by fermentation were reflected in the optical properties of fermented oat milk, since significant differences were observed in colour parameters between non-fermented and fermented products. Lightness and hue parameters increased after the fermentation process, while chrome decreased ( $\mathrm{p}<0.05$ ). Nevertheless, the total colour difference between fermented and non-fermented oat 
milks ( $\Delta \mathrm{E}$ ) was very small since, according to Francis (1983), values lower than 3 units cannot be easily detected by the human eye.

\section{CONCLUSIONS}

The Response Surface Methodology was used to identify the levels of the different growth factors which permit an optimal oat milk formulation for the fermentation process to be obtained with starter bacteria, L. reuteri ATCC 55730 and S. thermophilus CECT 986. The defined oat formulation achieved a starter survival above the minimum level suggested for ensuring health benefits $\left(10^{7} \mathrm{cfu} \mathrm{mL}^{-1}\right)$ and so it can be considered as a functional food. The starter viability was maintained during the whole shelf life typical of this kind of product. The metabolic activity of the starters remained during cold storage due to the availability of nutrients, of which, as expected, monosaccharides are mainly consumed. Thanks to their high stability, a reasonable ratio of oat $\beta$-glucans remained in the final fermented products which have a positive effect on the product matrix structure, due to their thickening and gelling properties. Besides the technological advantages, these compounds, together with the added inulin, make the product one of great nutritional interest, since both of them are stated as prebiotics. Thus, consumers might benefit from both the nutritional and health properties of these functional food ingredients: probiotics and prebiotics. Sensory evaluation showed there was a good acceptance of the developed oat fermented product until 14 days of cold storage, ensuring good sweetness, acidity and consistency. Nevertheless, despite the probiotic viability, its shelf-life would be shorter than that of the standard yoghurts from the point of view of its sensory acceptance.

\section{REFERENCES}

Allgeyer LC, Miller MJ and Lee SY (2010) Sensory and microbiological quality of yogurt drinks with prebiotics and probiotics. Journal of Dairy Science 93(10): 4471-4479.

Angelov A, Gotcheva V, Kuncheva R and Hristozova T (2006) Development of a new oat-based probiotic drink. International Journal of Food Microbiology 112(1):75-80. 
Årsköld E, Lohmeier-Vogel E, Cao R, Roos S, Rådström P and van Niel WJ (2008) Phosphoketolase pathway dominates in Lactobacillus reuteri ATCC 55730 containing dual pathways for glycolysis. Journal of Bacteriology 190(1): 206-212.

Årsköld E, Svensson M, Grage H, Roos S, Rådström P, Ed WJ and van Niel WJ (2007) Environmental influences on exopolysaccharide formation in Lactobacillus reuteri ATCC 55730. International Journal of Food Microbiology, 116(1): 159-167.

Bender FE, Douglas LW and Kramer DS (1989) Statistical methods for food and agriculture. Avi Westport: Publishing Co Inc.

Cheng H (2010) Volatile Flavor Compounds in Yogurt: A Review. Critical Reviews in Food Science and Nutrition 50(10): 938-950.

Cruz AG Faria JAF Walter EHM Andrade RR Cavalcanti RN Oliveira CAF and Granato D (2010) Processing optimization of probiotic yogurt containing glucose oxidase using response surface methodology. Journal of Dairy Science 93(11): 5059-5068.

FAO/WHO (2001) Report on Joint FAO/WHO Expert Consultation on Evaluation of Health and Nutritional Properties of Probiotics in Food Including Powder Milk with Live Lactic Acid Bacteria. Available at: http://www.who.int/foodsafety/publications/fs_management/en/probiotics.pdf. (accessed 12 june 2012).

Francis FJ (1983). Colorimetry of foods. In: Pelef M and Baglet EB (eds), Physical Properties of Foods. Westport: AVI Publishing Co Inc, pp. 105-124.

Gibson GR, Probert HM, Van Loo J, Rastall RA and Roberfroid MB (2004) Dietary modulation of the human colonic microbiota: updating the concept of prebiotics. Nutrition Research Review 17(2): 259-275.

Gomes AMP and Malcata FX (1999) Bifidobacterium spp. and Lactobacillus acidophilus: Biological, biochemical, technological and therapeutical properties relevant for use as probiotics. Trends in Food Science and Technology 10(4-5): 130-157.

Granato D, Branco G, Nazzaro F, Cruz A and Faria JAF (2010) Comprehensive Reviews in Food Science and Food Safety 9(3): 292-302.

Gupta S, Cox S and Abu-Ghannam N (2010) Process optimization for the development of a functional beverage based on lactic acid fermentation of oats. Biochemical Engineering Journal 52(2-3): 199-204. 
Horwitz W (2000) Official Methods of Analysis of AOAC International. Gaithersburg: Association of Official Analytical Chemists.

International IDF Standard (1997) Dairy starter cultures of Lactic acid Bacteria (LAB): Standard of identity. Brussels: International Dairy Federation.

Johansson ML, Molin G, Jeppsson B, Nobaek S, Ahrné S and Bengmark S (1993) Administration of different Lactobacillus strains in fermented oatmeal soup in vivo colonization of human intestinal mucosa and effect on the indigenous flora. Applied and Environmental Microbiology 59(1): 15-20.

Lazaridou A and Biliaderis CG (2007) Molecular aspects of cereal $\beta$-glucan functionality: Physical properties, technological applications and physiological effects. Journal of Cereal Science 46(2): 101-118. Lourens-Hattingh A and Viljoen BC (2001) Yogurt as probiotic carrier food. International Dairy Journal 11(1-2): 57-62.

Marcel B and Roberfroid MB (2000) Prebiotics and probiotics: are they functional foods? American Journal of Clinical Nutrition 71(6): 1682s-1687s.

Mårtensson O, Andersson C, Andersson K, Öste R and Holst O (2001) Formulation of a fermented product from oats and its comparison to yoghurt. Journal of Science and Food Agriculture 81(14): 1413-1421.

Mårtensson O, Öste R and Holst O (2000) Lactic acid bacteria in an oat-based non-dairy milk substitute: Fermentation characteristics and exopolysaccharide formation. Food Science and Technology 33(8): 525530.

Mårtensson O, Öste R and Holst O (2002) The effect of yoghurt culture on the survival of probiotic bacteria in oat-based, non-dairy products. Journal of Food Research International 35(8): 775-784.

Matissek R, Schnepel FM and Steiner G (1998) Determinación de azúcares totales: método reductométrico de Luff-Schoorl. In: Matissek et al. (eds), Análisis de los Alimentos: Fundamentos, Métodos y Aplicaciones. Zaragoza: Acribia SA publishings, pp. 123-132.

Mattila-Sandholm T, Myllärinen P, Crittenden R, Mogensen G, Fondén R and Saarela M (2002) Technological challenges for future probiotic foods. International Dairy Journal 12(2-3): 173-182.

McClements DJ (2004) Food Emulsions: Principles, Practices and Techniques. Boca Raton: CRC Press. 
Mistry VV and Hassan HN (1992) Manufacture of nonfat yogurt from a high milk protein powder. Journal of Dairy Science 75(4): 947-957.

Piotrowska A, Waszkiewicz-Robak B and Swiderski F (2009) Possibility of beta-glucan spent brewer’s yeast addition to yoghurts. Polish Journal of Food and Nutrition Sciences 59(4): 299-302.

Roberfroid MB (2005) Introducing inulin-type fructans. British Journal of Nutrition 93(1): S13-S25.

Sadiq-Butt M, Tahir-Nadeem M, Iqbal-Khan M, Shabir R and Butt SM (2008) Oat: unique among the cereals. European Journal of Nutrition 47(2): 68-79.

Sahan N, Yasar K and Hayaloglu AA (2008) Physical, chemical and flavour quality of non-fat yogurt as affected by a b-glucan hydrocolloidal composite during storage. Food Hydrocolloids 22(7): 1291-1297.

Sharareh H, Hoda S and Gregor R (2009) Growth and survival of Lactobacillus reuteri RC-14 and Lactobacillus rhamnosus GR-1 in yogurt for use as a functional food. Innovative Food Science and Emerging Technologies 10(2): 293-296.

Stanton C, Desmond C, Coakley M, Collins JK, Fitzgerald G and Ross RP (2003) Challenges facing in development of probiotic containing functional foods. In: Farnworth E (ed), Handbook of Fermented Functional Foods. Boca Raton: CRC Press, pp. 27-58.

Sumangala G, Lanwei Z, Ming-Kuei H, Xin Z and Mingruo G (2005) Oat-based synbiotic beverage fermented by Lactobacillus plantarum, Lactobacillus paracasei ssp. casei, and Lactobacillus acidophilus. Journal of Food Science 70(4): 216-223.

Tamime AY and Robinson RK (2000). Yoghurt. Science and Technology. Boca Raton: CRC Press.

Tosh SM, Marangoni AG, Hallett FR and Britt IJ (2003) Aging dynamics in gelatin gel microstructure. Food Hydrocolloids 17(4): 503-513.

Van Niel CW, Feudtner C, Garrison MM and Christakis DA (2002) Lactobacillus therapy for acute infectious diarrhea in children: a meta-analysis. Pediatrics 109(4): 678-684.

Vasiljevic T, Kealy T and Mishra VK (2007). Effects of $\beta$-glucan addition to a probiotic containing yogurt. Journal of Food Science 72(7): C405-C410. 
Velasco SE, Areizaga J, Irastorza A, Dueñas MT, Santamaría A and Muñoz ME (2009) Chemical and rheological properties of the $\beta$-glucan produced by Pediococcus parvulus 2.6. Journal of Agriculture and Food Chemistry 57(5): 1827-1834.

Wisselink HW, Weusthuis RA, Eggink G, Hugenholtz J and Grobben GJ (2002) Mannitol production by lactic acid bacteria: a review, International Dairy Journal 12(2-3): 151-161.

Yaakob H, Ahmed NR, Daud SK, Malek RA and Rahma, RA (2012) Optimization of ingredient and processing levels for the production of coconut yogurt using response surface methodology. Food Sciences and Biotechnology 21(4): 933-940. 